of the iris in the wound and to replace the temporal pillar into the anterior chamber. The final result gives a better cosmetic effect and retains the sphincter action of the pupil, and has been found to provide an adequate fistula at the same time.

Gentle massage and drops of pilocarpine $\frac{1}{2}$ per cent., or of pilocarpine and adrenalin, are required as post-operative measures for one to three months, as in the case of most iridencleisis operations. Indeed I prefer to institute a permanent post-operative routine of the daily use of pilocarpine in all such cases as a precautionary measure of control of the whole uveal tract, since any type of fistula can contribute only a very small additional fraction to the total drainage mechanism, and since the primary fault lies perhaps in the vascular tope of the uvea rather than in the filtration of fluid.

\title{
A CASE OF REMOVAL OF NON-MAGNETIC FOREIGN BODY FROM THE CILIARY REGION \\ BY
}

\section{Dermot Pierse}

LONDON

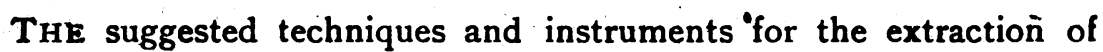
non-magnetic foreign bodies from the vitreous chamber are many. Much ingenuity has resulted in such various methods as Cruise's telephone probe, Thorpe's endoscope, biplane fluoroscopy and so on. Equally noticeable, however, is the paucity of actual details of cases successful or unsuccessful.

Where the foreign body lies free in a clear vitreous, Spaeth recommends that either the endoscope or biplane fluoroscopy be used, but says that if it lies in contact with the retina or ciliary body, some form of flap sclerotomy following accurate localisation is the proper procedure. Savin in his Hunterian lecture earlier this year, mentioned that he was able to find only one successful case recorded in the literature. It was on his account of Spaeth's technique that this operation was based.

\section{Case Report.}

J. B., a male aged 38 years was watching a fellow worker turning a brass bolt; when the tool slipped and he felt a sharp pain in the right eye. On examination a few hours later it was found that a small foreign body had perforated the right cornea just above its centre and travelling downwards, had driven through the root of the 
iris below. : The edge of what appeared to be a fragment of metal was just visible in the angle of the anterior chamber.

The lens was clear. Fundus-no abnormality detected. Vision $=6 / 9$. Left eye-no abnormality detected - Vision $=6 / 6$.

As there was no response to the giant magnet it was decided to try removal through a corneal incision. On attempting to grasp it with iris forceps, however, it disappeared backwards through the hole in the root of the iris. It was then decided to localise it accurately and approach it by the posterior route. Localisation was achieved by inserting a needle into the sclera at the estimated

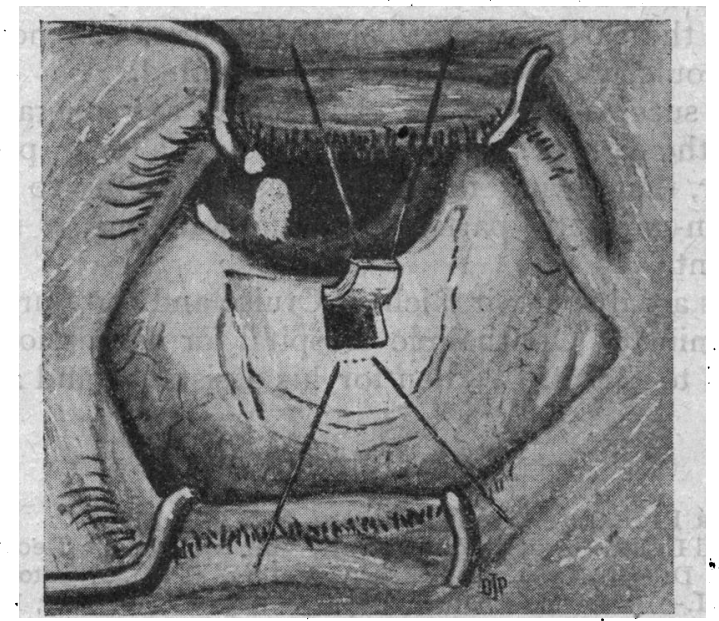

Figure showing scleral flap held úp by suture.

site of the foreign body. An X-ray film showed the exact position in relation to the needle point. This was about four $\mathrm{mm}$. from the limbus and about one mm. deep from the scleral surface. From this it was considered to be lying posterior to the zona ciliaris, either in the vitreous or in the adjoining ciliary body.

The patient was then given a retrobulbar injection of novocaine and facial akinesia. The conjunctiva was incised around the lower third of the limbus and retracted from the site of operation. Two bites of a scleral suture were made about four $\mathrm{mm}$. from the limbus. The sclera was then divided between them, parallel to the limbus, for about three $\mathrm{mm}$. The incision was gradually deepened by careful dissection until the ciliary body appeared and then converted into a flap, hinged at the limbus. The presenting ciliary body was investigated with the point of the knife until the foreign body was felt, when it was easily removed through the ciliary body. It 
proved to be a pyramidal shaped piece of brass about three $\mathrm{mm}$. high. The scleral flap was closed by means of the previously inserted suture and the conjunctiva replaced.

The post-operative period was satisfactory and the patient left hospital after a fortnight. On examination a month later the patient had a white eye with no sign of bulging in the area of the flap. There was some very fine pigment disturbance on the back of the cornea. Lens and fundus-no abnormalities. Vision with -0.75 cyl. axis $175^{\circ}-6 / 6$.

Many surgeons advise immediate X-ray of every perforating injury, whether or not a foreign body is visible. It is interesting to note that had this been done in this case it would have revealed the blunt end of the particle lying behind the iris. Removal through the cornea would not then have been attempted.

Complete success cannot be claimed for any operation of this , nature until the case has been observed over a long period. It is felt, however, that owing to the increased liability to intra-ocular injury by non-magnetic particles during war-time, it is worthy of note at present.

My thanks are due to Sir Richard Cruise and the Surgeons of the Royal Westminster Ophthalmic Hospital for permission to publish this case and to Mr. P. L. Allen for his assistance and advice.'

\title{
REFERENCES
}

1. CRUise, Sir Richard.-Trans. Ophthal. Soc, U.K., 1915.

2. BoRLeY and LEef.-Amer. Jl. Ophthal., Vol. XX, No. 12, December, 1937.

3. SPaETh, E. D.-Ji. Amer. Med. A ssoc., Vol. CXX, No. 9, October, 1942.

4. SAvin, L. H.-Hunterian Lecture, Royal College of Surgeons, 1943. (Pending publication).

\section{AN INTERESTING CASE OF RUPTURE OF THE CHOROID}

\author{
BY. \\ Captain Emanuel Rosen, M.C.
}

THE case reported by Humphrey Neame " Multiple Ruptures of the Choroid with Retention of Good Vision" in the Brit. Jl. Ophthal., p. 399, 1940, has come to my attention and it is for this reason that $I$ am submitting the following case:

J. S., aged 33 years, suffered an injury to his tight eye when he was chopping wood-he was struck. by an end over end flying piece of wood. Although there was severe damage to the eye, the patient does not recall having been attended by an oculist. He does not 